Internal Report

DESY M-81/07

March 1981

D. Degèle, H.C. Dehne, H. Gerke, D. Heins, K. Hoffmann, R.D. Kohaupt,

R. Kose, H. Kumpfert, M. Leneke, H. Mais, H. Nesemann, S. Pätzold,

F. Peters, A. Piwinski, J. Roßbach, R. Rossmanith, K. Steffen,

G.A. Voss, K. Wille, A. Wrulich

Paper to be presented at

the 1981 Particle Accelerator Conference

Washington, D.C., March 11-13, 1981 


\section{NEW DEVELOPMENTS AT PETRA}

PETRA Storage Ring Group ${ }^{*}$

Presented by J. Rossbach

Deutsches Elektronen-Synchrotron DESY

2000 Hamburg 52, Germany

\section{Summary}

Installation of "mini-B-inserts", addition of 2nd harmonic cavities, and increase of energy are the main efforts at PETRA now. By reducing the free space for the high energy physics detectors to $\pm 4.45 \mathrm{~m}$ the beta-functions at the interaction points can be decreased to $6 \mathrm{~cm}$ vertically and $130 \mathrm{~cm}$ horizontally, thus decreasing the beam size by a factor of 2.5 . First results of operation are presented. Theory and some experimental evidence show that with the help of 2 nd harmonic cavities ( $1 \mathrm{GHz}$ ) both a vertical single bunch instability and synchro-betation resonances can be cured. The $1 \mathrm{GHz}$ system under construction will be able to reduce the longitudinal focusing in the bucket center to zero up to 11 GeV particle energy. In order to increase the maximum PETRA energy for luminosity runs from 36.7 $\mathrm{GeV}$ to $41.4 \mathrm{GeV}$ and later on to $45.0 \mathrm{GeV}$., the $500 \mathrm{MHz}$ If system will be extended. First, the number of rf-transmitters will be doubled, and in a second step additional new type seven-cell cavities will be installed.

\section{Introduction}

The electron positron storage ring PETRA in Hamburg is by now an established machine, having provided during the last $21 / 2$ years five high energy physics detectors with luminosity. About 200 high energy physics papers are based on experimental results from PETRA.

The PETRA performance at the end of 1980 was as follows:

*D. Degèle, H.C. Dehne, H. Gerke, D. Heins,

K. Hoffmann, R.D. Kohaupt, R. Kose,

H. Kumpfert, M. Leneke, H. Mais,

H. Nesemann, S. Pätzold, F. Peters,

A. Piwinski, J. Roßbach, R. Rossmanith,

K. Steffen, G.A. Voss, K. Wille,

A. Wrulich

\begin{tabular}{|c|c|c|c|c|c|}
\hline If-power & $\begin{array}{l}\text { number of } \\
5 \text {-cell cavities }\end{array}$ & $\begin{array}{l}\text { number of } \\
7 \text {-cell cavities }\end{array}$ & $\begin{array}{l}\text { total shunt } \\
\text { impedance } R_{S}=\frac{V^{2}}{2 P}\end{array}$ & $\begin{array}{l}\text { maximum c.m.en } \\
\text { for luminosity }\end{array}$ & $\begin{array}{l}\text { ergy } \\
\text { operation }\end{array}$ \\
\hline $\begin{array}{l}4.4 \mathrm{MW} \\
(4 \times 1.1 \mathrm{MW})\end{array}$ & $4 \times 15$ & 0 & $1080 \mathrm{M}$ & $36.72 \mathrm{GeV}$ & \\
\hline $\begin{array}{l}\text { lst step } 8.8 \mathrm{MW} \\
(82) \quad(8 \times 1.1 \mathrm{MW})\end{array}$ & $8 \times 8$ & 10 & $1402 M$ & $41.4 \mathrm{GeV}$ & \multirow{2}{*}{$\begin{array}{l}\text { scaled from } \\
\text { existing } \\
36.72 \mathrm{GeV}\end{array}$} \\
\hline $\begin{array}{l}\text { 2nd step } 8.8 \mathrm{MW} \\
(82 / 83)(8 \times 1.1 \mathrm{MW})\end{array}$ & $8 \times 8$ & $8 \times 8$ & $2752 M$ & $45.0 \mathrm{GeV}$ & \\
\hline
\end{tabular}

$22 \%$ of the year was scheduled for machine studies and preparations, $28 \%$ for shut downs, $4 \%$ for holidays, and $46 \%$ for high energy physics runs. The average luminosity per interaction point during that time - including all machine break downs and including the time spent pn injection and accejderation - was $47 \mathrm{nb}^{-1}$ per day or $0.56 \times 10^{3} \mathrm{~cm}^{-2} \mathrm{~s}^{-1}$. This corresponds to a total of $32000^{\mathrm{nb}} \mathrm{b}^{-1}$ produced in PETRA in 1980. The average of $47 \mathrm{nb}^{-1}$ includes many runs at the highest energies up to $18.36 \mathrm{GeV}$ per beam, where due to the Iimited If-power peak luminosities drop to

$0.8 \times 10^{30} \mathrm{~cm}^{-2} \mathrm{~s}^{-1}$ and integrated over a day to values of 20 to $40 \mathrm{nb}^{-1}$. The optimal energy for luminosity operation was 17.8 GeV where

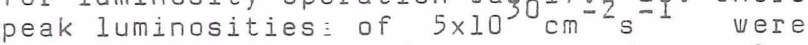
reached and integrated over a day values of $150 \mathrm{nb}^{-1}$.

The ongoing machine development program at PETRA aims at an increase of energy and increase of luminosity. For higher energies, the acceleration voltage has to be increased. More luminosity is made possible to some extent by higher beam currents - at least at c.m. energies between 30 and $34 \mathrm{GeV}$, where the luminosity in routine operation has been current limited up to now. Each sugcess in reduction of beam beam interaction raises the importance of this aspect. At all energies more luminosity is gained by smaller beta functions at the interaction points.

It has been decided at PETRA to take all three measures, and first experimental results of one of them, the mini beta scheme, are presented in this paper.

\section{Rf-extension}

Table 1 summarizes the present situation (March 81) and further steps to extend the PETRA acceleration If system.

Table 1: Development of PETRA $500 \mathrm{MHz}$ acceleration If-system 


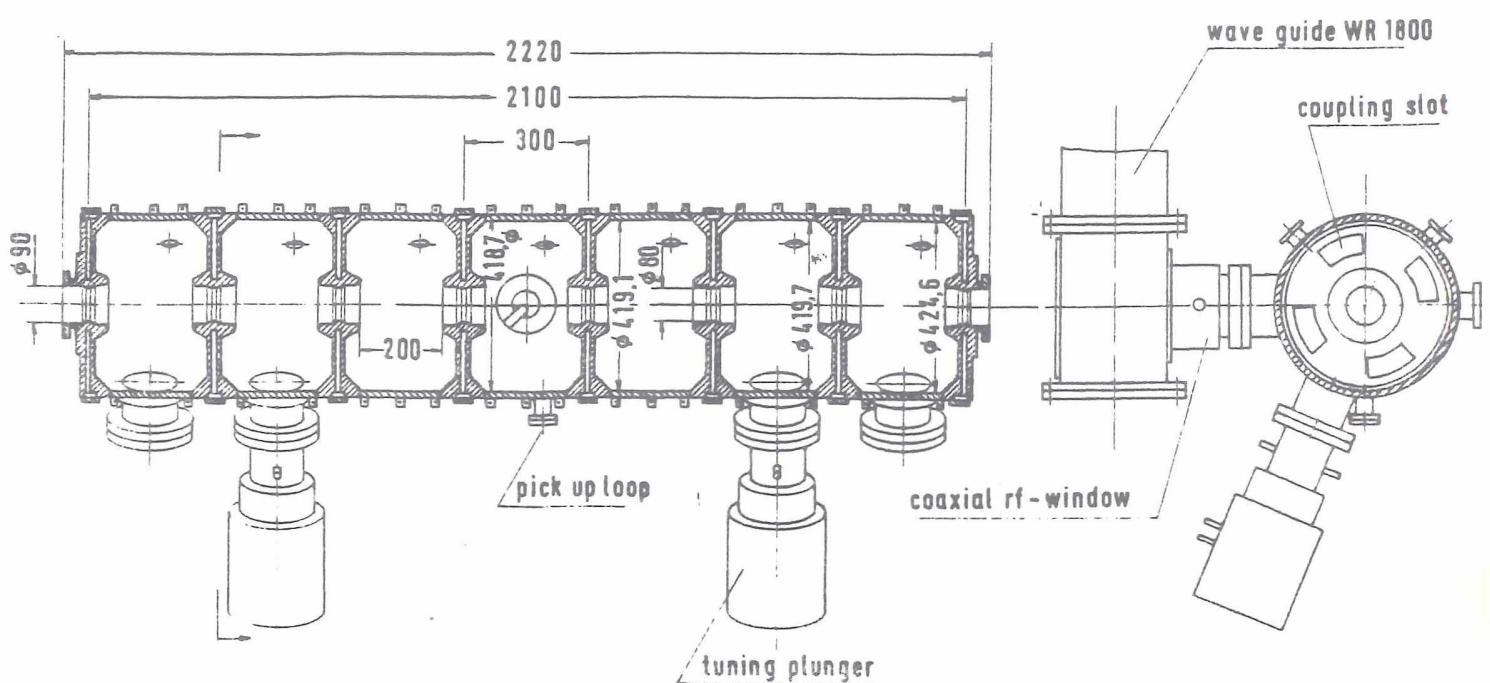

Fig. 1: PETRA new type 7-cell acceleration cavity (500 $\mathrm{MHz}$ )

Four transmitters with two $550 \mathrm{~kW}$ klystrons each are installed now to power four groups of 15 cavities in the north and south straight sections. In a first step (spring 82 ) the number of transmitters will be doubled and existing cavities will be rearranged to form a fourfold symmetry. This will bring the maximum c.m. energy for luminosity operation to $40.4 \mathrm{GeV}$. Addition of 10 more cavities during 1982 will increase this energy to $41.4 \mathrm{GeV}$. These and all cavities which are added later will be new 7-cell structures with two plungers; their shunt impedances $\left(V^{2} / 2 P\right)$ will be as high as 25 M $\Omega$. Figure 1 shows the geometry of these new cavities in detail.

The second step (1983) brings the total to 128 cavities and increases the maximum $c \cdot m$. energy for luminosity operation to $45.0 \mathrm{GeV}$.

\section{2nd harmonic system}

At first sight there seems to be no need of higher beam currents in PETRA: The maximum currents, which have been stored up to now in luminosity optics $(4 \times 6 \mathrm{~mA})$, are more than space charge forces vill permit in the colliding beam mode.

On the other hand there are promising techniques within reach to reduce beam beam interaction ${ }^{2}$, and the planned increase of beam energy will allow interaction of higher currents, too. Moreover, PETRA operation at high currents is quite critical now and careful adjustments are necessary.

There are two effects which make storage of higher currents in PETRA difficult: a vertical single bunch instability and satellite resonances. Since both of them are particularly troublesome at the injection energy of $7 \mathrm{GeV}$ and during the beginning of the energy ramping, the cure needs not to be extended to energies $E \gtrsim 10 \mathrm{GeV}$.

There are good theoretical reasons ${ }^{2}$ ) and experimental hints ${ }^{3}$ that both effects can be decisively reduced with the help of higher harmonic cavities. The effect of these cavities will be to reduce the longitudinal focusing in the bucket center to zero, thereby lengthening the bunches. This should reduce the single bunch instabilities. Also the synchrotron frequency becomes very amplitude dependent. This should reduce satellite resonance excitation.

In a first step (by mid 81) $81000 \mathrm{MHz}$ cavities will be installed, driven by one $125 \mathrm{~kW}$ klystron. Up to $11 \mathrm{GeV}$ it will be possible to maintain a nearly zero longitudinal focusing force near the bucket center with quite strong "walls". This will result in a five times larger bunch length. The second step will be - of course dependent on the results of step one - a second $125 \mathrm{~kW}$ transmitter, to increase the maximum energy with full effect up to $12 \mathrm{GeV}$. All $1000 \mathrm{MHz}$ cavities will be 7 -cell structures with $120 \mathrm{~mm}$ aperture. Figure 2 shows details.

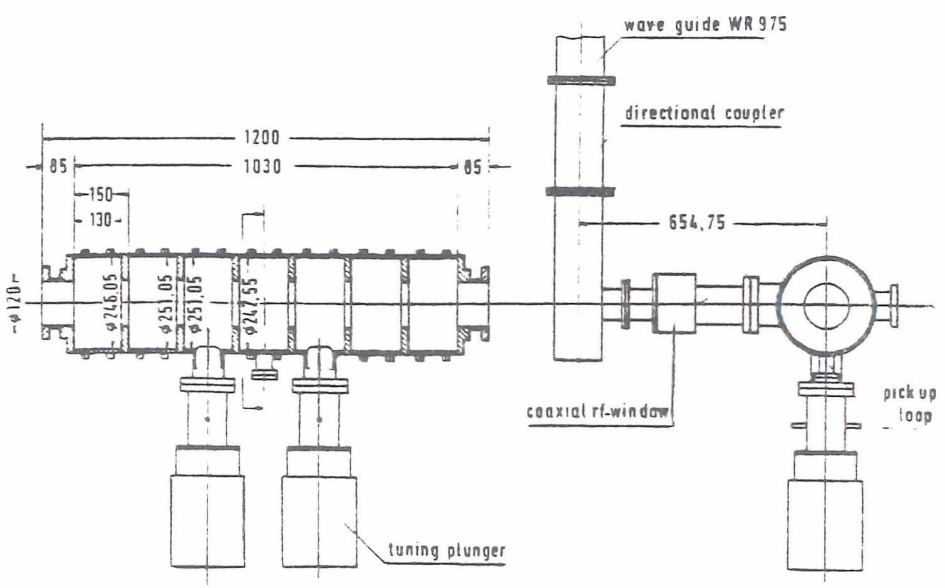

Fig. 2: PETRA 2nd harmonic ( $1000 \mathrm{MHz}$ ) cavity 


\section{PETP.A mini beta inserts}

At the time when the geometry of the interaction regions was fixed it was thought that there would be no severe beambeam-interaction below a linear tune shift of $\Delta \xi=.06$ per interaction point. We now find that the beam-beam-interaction widens the vertical beam size considerably at $\Delta \xi=$ .015 already ${ }^{4}$. Not even with sophisticated methods emerging from computer simulations ${ }^{1}$ much more than.03 has been reached. To recover the lost factor in luminosity we decided to reduce the total drift length from $15 \mathrm{~m}$ to $8.9 \mathrm{~m}$ in all four interaction regions. Besides the addition of the mini beta quadrupoles no other quadrupoles were changed in position. Figure 3 shows the envelopes near the interaction points for the extreme mini beta optics MI 6 and for the previous luminosity optics.

The new beta values are $6 \mathrm{~cm}$ vertically and $130 \mathrm{~cm}$ horizontally as compared to $17 \mathrm{~cm}$ and $280 \mathrm{~cm}$ in last year's luminosity optics. The beam cross-section decreases and specific luminosity increases therefore by a factor of about 2.5. It is seen that the whole job is done without any increase of the maximum beta functions. On the contrary the horizontal physical acceptance is increased from $20 \pi \mathrm{mradmm}$ to $30 \mathrm{~mm} r \mathrm{admm}$. The linear chromaticity increases mainly due to the shorter focal lengths of the mini beta quadrupoles.

But even for the same linear chromaticity like before, the mini beta scheme would provide a smaller beam size at the interaction point by a factor of 2 .

The mini beta scheme came into operation in Feb. 81 . Two weeks later $4 \times 8 \mathrm{~mA}$ vere stored in two electron and two positron bunches at $7 \mathrm{GeV}$ in a special injection optics. $4 \times 6 \mathrm{~mA}$ can be transferred from injection optics at $7 \mathrm{GeV}$ to luminosity optics at high energies. The lifetime at $17 \mathrm{GeV}$ is good, indicating that there is sufficient acceptance. So far

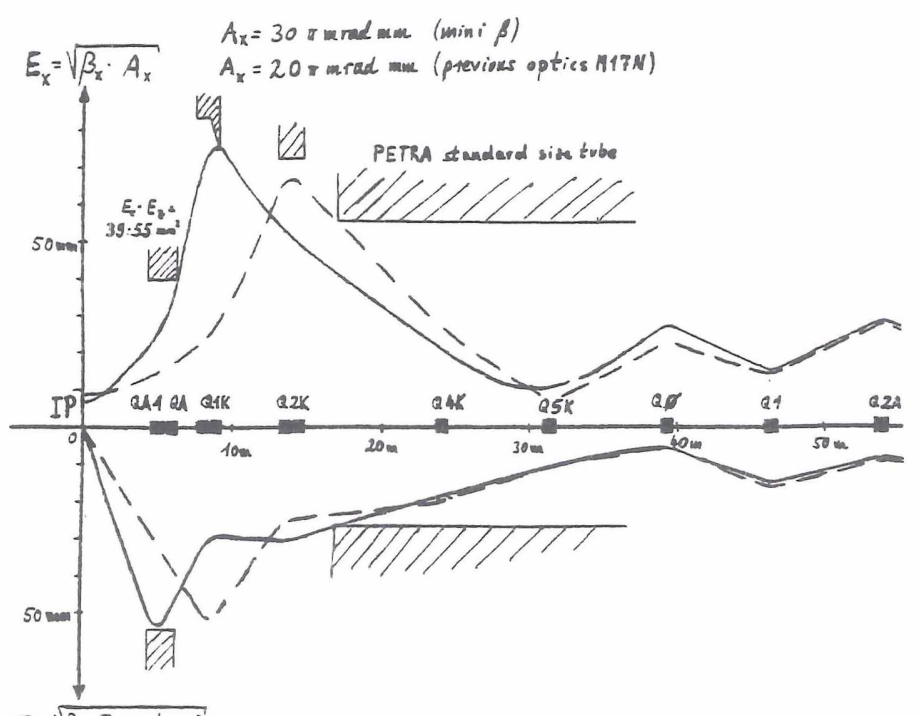

Fig. 3: Horizontal and vertical envelopes near the interaction point previous running conditions seem to be restored. For luminosity optics the beta functions at the interaction points were checked at differentenergies and are in good agreement with calculations. The same holds for the horizontal emittance.

The observations of beam-beam-effects and measurements of the luminosity have only started. Especially luminosity measurements at more than $16 \mathrm{GeV}$ still suffer from high background rates. But first results at $14 \mathrm{GeV}$ are encouraging.Figure 4 shows measurements of the luminosity with $2 \times 2$ bunches at tunes of $Q=25.2, Q_{z}=23.3, f=10 \mathrm{kHz}$. It is hard to compâre in such an ear Iy stage these measurements with earlier luminosity runs, which had been optimized to a high degree. A typical previous luminosity curve (not the best one) is shown in comparison. It seems, that the luminosity might be up by the expected factor of 2.5 and that the beam-beam-interaction forces as measured by the linear tune shift are not more destrucitve when $\beta$ is reduced to such small numbers.
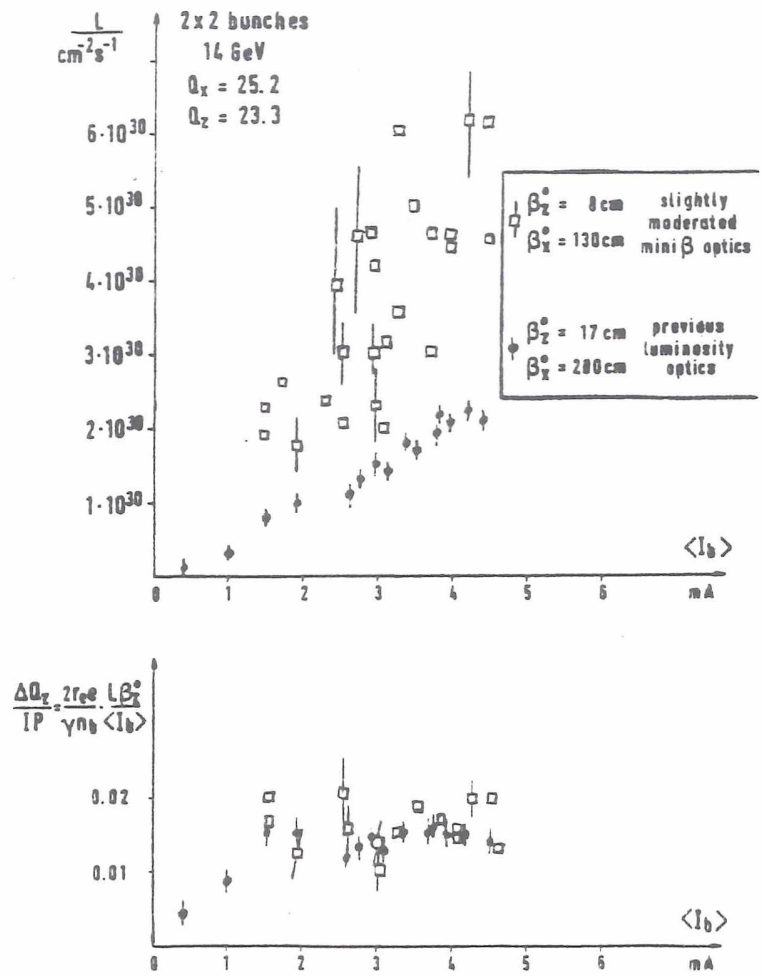

Fig. 4: Comparison of measured luminosity and vertical linear tune shift at $14 \mathrm{GeV}$ with $2 \times 2$ bunches as a function of bunch current $I_{b}$

\section{References}

1) A. Piwinski: Computer simulations of the beam-beam-interaction and measurements with PETRA, DESY, contr. to this conference

2) R.D. Kohaupt: Head-tail-turbulence and the transverse PETRA instability, DESY $80 / 22$ (1980)

3) M.H.R. Donald, J.M.Paterson: An investigation of the "flip-flop" beam-beam effect in SPEAR, 1979, IEEE Trans.Nucl.Sc.,NS26,3

4) A. Piwinski: Observation of beam-beam effects in PETRA, DESY Internal Report $M-79 / 11(1979)$ 